\title{
Languages, Symbolic Power and Multidimensional Poverty in the Context of Pakistan
}

\author{
Assoc. Prof. Dr. Tayyaba Tamim \\ Department of Social Sciences, Senior Research Fellow, \\ Centre for Research and Economics, Lahore School of Economics
}

\begin{abstract}
This paper engages with the question of languages in education and language policy in the multilingual context of Pakistan, from the perspective of its impact on multidimensional poverty. Poverty is interpreted as 'capability deprivation' following Amertya Sen's capability approach, while Bourdieu's social critical theory inform the analysis. The paper is based on findings from a 3-year qualitative study, funded by Research Consortium on Educational Outcomes and Poverty (RECOUP). The methods of data collection included participant observation, documentary analysis and interview data from 16 cases of private and government school graduates, in two provinces. Each case comprised of a final-year secondary school student and his/ her same sex 5-6 year older sibling. The findings reveal that the symbolic power of English in the country, in contrast to its restricted access, and the concurrent devaluation of the local linguistic capital reinforced the structures that nest inequality and poverty. This restrained the agency and of the already socioeconomically disadvantaged government school participants to achieve valued goals as inequality was unleashed in the multiple dimensions of their lives: cognitive, social, affective, economic, and physical. The paper argues for more inclusive language policies and languages in education.
\end{abstract}

Keywords: Languages; Symbolic power; Education; Inequality and Poverty; Bourdieu; Capability approach

\section{Introduction}

The question of languages in education and language policy has been a subject of much debate among policy makers and academics given the paradoxical tensions inherent in the decision, specifically in postcolonial multilingual country contexts. On the hand are the pragmatic concerns of efficiency that favour continued the use of colonial language; On the other hand are the political exigencies of emphasizing national identity, or addressing ethnic rivalries. This is not to mention the complexity such decisions carry because of its juxtaposition between meeting local vs. global communication needs.

Language not only mediates education, as a medium of subject study and the appropriation of knowledge as emphasized by sociocultural theory ( Lantolf, 2001) but delimits wider access and participation. The choice of languages to be taught in schools and language related practices are charged with social, cultural and historical context 'intimately related to the distribution of social power and hierarchical structures in society' (Gee, 1989: 20; Bourdieu, 1991). As such, language can act as a subtle yet potent means of exclusion both within education and in wider social context (ibid.).

The core of this issue resides in the configuration of economic and political power, which maintains the dominance of the privileged through language policy and planning (Nyati-Ramahobo, 2004). It is important then that languages in education and language policies are analyzed with reference to the wider sociopolitical, ideological, and linguistic hierarchical structures that exist in the society' (Devine, 1994: 231).

The construct of poverty is linked with the concept of development, as the latter is based on an understanding of the former. If poverty is conceptualized as multidimensional, and as constraint on one's choices or 'capabilities' to achieve valued choices, then moving towards development would mean freedom from 'control,' and freedom to 'achieve,' an enhancement of 'a person's ability to do or be what one values' (Sen, 1999: 68). This notion of freedom captures a strengthened ideal of a person, as an 'active' agent rather than a 'passive' recipient of aid (Sen, 1990: 44). From this point of view, development is about 'removing the obstacles to what a person can do in life, such as illiteracy, ill health, lack of access to resources, or lack of civil and political freedom' (Fakuda-Parr, 2003: 303). 
The link between language policy and development is emphasized by Kaplan and Baldauf, (1997), who argue that language policies are intimately linked to human resource development. If not based on principles of equity and justice, language policies can marginalize certain groups, constrict their agency, affect their identity and reinforce if not aggravate issues of poverty. Language policies can bring people to centre stage or reduce them to the periphery of development and limit their participation in the state affairs (Markee, 2002). If development is to be a step towards 'self actualization', as envisaged by the capability approach, what is needed then is to ensure a 'two-way communication' and participation rather than a 'topdown intervention,' accepting the potential of culture (Dubbeldam, 1984 in Robinson, 1996:45).

Robinson's (1996) research found language acted as a tool of gender and ethnic exclusion from processes of socioeconomic development (Robinson, 1996), that led him to question why the poorest populations also tended to be linguistically most marginalized (Ibid.). Other sociolinguistic studies (Tollefson, 1991; Skutnabb Kangas, 1998; Rahman, 2006) also highlighted the marginalizing impact of post colonial languages. However, the interlink between languages in education, as embedded within the macro national language policy and narrowly defined poverty as experienced by those involved remains largely neglected.

This paper based on the key findings of a wider 3-year study explores the question: What is the role of languages in education and language policy in addressing poverty in the multilingual context of Pakistan? The construct of poverty is conceptualized as relative and evaluated as 'capabilities' or expansion of effective choices to achieve valued beings and doings i.e. 'functionings' (Sen, 1990). The study uses a qualitative multiple case study design and Pierre Bourdieu's social critical theory with specific reference to his work on symbolic power to analyse the findings. The results of the study are limited owing to its design. Nevertheless, the paper offers in depth insights into the processes of inequality in multiple dimensions of participants' lives through a comparison of the experiences of private and government school graduates affected by their learning of languages.

The next section briefly discusses the theoretical framework, followed by an overview of the context of the study and then its methodology. After this findings are discussed and then the paper is concluded.

\section{Theoretical Framework: Bourdieu and Symbolic Power}

Bourdieu emphasizes that 'the social world presents itself, objectively as a symbolic system which is organized according to the logic of difference, of differential distance' (Bourdieu, 1989, p. 132). The key to understand this symbolic system, which comprises objective realities of the given context and the intersubjective meanings assigned to them by agents is the notion of capitals. It is the structure and volume of capitals (potential or actual resources): economic, social and cultural and symbolic, accumulated over time, that position individuals differentially in a hierarchical social space of relative power, shared with others similarly positioned (Bourdieu, 1986). The value assigned to capitals, however, is an arbitrary act, though misrecognized as natural and common sense. This misrecognition makes it not only difficult to question the valuation but also enables certain capitals to acquire a 'symbolic power.' Hence they become a tacit source of cultural and social domination without the conscious realization of the dominated. The basis of symbolic power, then lies firmly in the 'misrecognition' or 'symbolic violence' that the rules of the game or the valuation system of the capitals are natural and absolute (Bourdieu, 1991). The valuation of capitals lies at the core of 'symbolic struggle' for distinction. As the agents engage in the symbolic struggle the dominated begin with the major set back that their capitals are poorly valued, while the dominant are privileged to succeed because they have more of the symbolic capital that counts in this struggle, they acquire the power to impose their world view (Bourdieu, 1986).

The dialectic between the objective and subjective realities is crystallized in Bourdieu's ( 1984) concept of habitus. The socialized self that internalizes the rules of the game so well that external limitations become limitations of the self and perceptions of what is possible (ibid.). Hence, individual habitus generates practices that align with the social group displaying 'a sense of one's place' or the distances to be maintained (Bourdieu, 1984: 471). Hence, habitus is becomes a tool of continuity of the given social order, yet paradoxically it is also the tool of change, since it evolves over time from exposure to different fields (ibid.). Similarly, social structures though relatively stable over time are vulnerable to change every time they are re-produced through symbolic struggles. Likewise, habitus is not a cultural static but becomes prone to change as it engages in these symbolic struggles. Hence, group positioning and memberships are not given once and for all. They have to be constantly maintained by establishing its distinction, and guarding its boundaries. Each member then assumes the dual role of representing the group as a whole and as a custodian of its boundaries, keeping others out 
(Blunden, 2011: 3). Bourdieu argues that to change the given social structures, one does not need a 'perfect fit,' (Cunningham, 1993) but reflexive thinking and understanding of the tools of symbolic dominance (ibid.)

Educational institutions are conceptualized as major sites of symbolic struggles and often vehicles of social reproduction (Bourdieu and Passeron, 1977 b). Schools not only privilege the cultural capital of the dominant as a norm, against which the dominated always appear deficient as their capitals are devalued. Different educational institutions tend to cluster children with specific cultural capital, and then differentially distribute the valued cultural capitals, for example language, in a way that the dominant, who already have a highly valued capitals, gain more of the symbolic capital. The power of the institutional authority triggers symbolic violence, i.e. a misrecognition that this valuation system is fair and natural, against which the failure of the dominated is only a result of their own lack of talent, forcing them to self-deselect from educational opportunity, or higher career aspirations. The mass education, Bourdieu (1977 b) argues only delays the elimination of the dominated from education when they are finally convinced that they do not have the natural ability to compete against those with superior in intellect (Bourdieu, 1989). It is the habitus that allows everyone to adjust to the given order of valuation, even when it works against them and later accept the harm done to them as deserved (Cunningham, 1993). It is the art of common sense i.e. the symbolic violence that forces the dominated to first to engage in a game in which they are bound to lose and become complicit in their domination, with the increasing symbolic power of the dominant.

Language can be a major source of discrimination both within education and in wider sociocultural context, as a subset of cultural capital. Linguistic exchanges for Bourdieu (1991) are 'situated encounters between agents, within social structures resulting from differential distribution of capitals (p. 2). As such language as a semiotic tool in interaction not only reflects traces of social structure of the context within which it is embedded, it re-enacts them and becomes implicit in re-establishing the symbolic system of differences. Hence, it itself becomes a site of symbolic struggle.

\section{Methodology}

The current study utilized a multiple case study design for in-depth insights into issues of multidimensional relative poverty in real life contexts, as experienced by the participants. The 16 cases were pairs of siblings of same gender educated from seven public and private schools in two different provinces in Pakistan. The main purpose for using siblings as participants was to understand the language teaching and learning experiences fresh in the minds of younger siblings and the impact of language learning on wider access and participation, as experienced by the older siblings. In addition, this provided insights into time related processes. The methods of data collection included: a) in-depth interviews, b) participant observation and c) documentary evidence. This paper mainly focuses on the interview data.

The cases were selected through purposive snowball sampling because of access issues at a time of political unrest when the data was being collected. The focus was to gather typical cases ${ }^{1}$ from private and government schools in two metropolitans. The two different regions in Pakistan were selected as case study sites with two different languages in education policy. In Karachi, (in the province of Sindh) all those appearing in the secondary school examination had to appear in a Sindhi language paper; while in Lahore (in Punjab) there was no such compulsion. All the schools were selected from urban areas.

The data analysis was a cyclical rather than a linear process, which can be roughly divided into two phases. In the first phase each interview was transcribed and analyzed individually and in the second phase data within and across the cases were analysed to look for emerging patterns and themes. The constant comparative method of the grounded approach to analyse data was adopted and themes were allowed to emerge from the data itself rather than imposing preconceived categories on it (Strauss \& Corbin, 1998). The process began with line-by-line coding of the transcribed interviews to get first impressions comprising mainly of the key words used by the participants, while taking notes or posting memos ${ }^{2}$ as some concepts seemed to develop. These codes were revisited more closely leading to the merging of the initial codes into more abstract categories. In the second phase the data across the cases was analyzed within specific domains. Later

\footnotetext{
1 This meant that these schools almost exemplified the majority of these school systems available to people in an Urban area, leaving out schools that were either too small or impoverished or those only for elites.

2 Memos are defined as ' the researcher's record of analysis, thoughts, interpretations, questions, and directions for further data collection' (Strauss and Corbin, 1998: 110)
} 
axial coding was used to identify recurring themes. These were finalized by more selective coding ${ }^{1}$ of the data at a higher degree of abstraction (Ibid.).

\section{The Context}

Pakistan, a postcolonial multilingual country, has at least 25 major languages with Urdu as the national and English as the official language. Hardly any role has been ascribed to regional languages, and it is left to the provinces to develop them as long as these are not in competition with the national language. The official status of English was always meant to be a temporary arrangement as also stated in the constitution of 1973, until Urdu could replace it.

However, English, the language of the colonial masters has not only firmly retained its position in the domains of power. It is the language of higher education, higher judiciary, businesses of large organizations, health sector and almost all the functionings of the government, where although Urdu might be spoken informally, yet English is the language of formal communication and documentation. Hence, the significance given to it by all for coveted jobs and upward social mobility is hardly surprising, despite the fact that it is Urdu mother language to $7 \%$ of the population that is the national lingua franca. The main source of the learning of Urdu and English are schools and regional languages are homes. However, there is exposure to Urdu in urban areas and to English also in correspondence with the socioeconomic background.

The two major educational systems in Pakistan (government and private) use languages differently in education. Government schools for the masses, offer free education in Urdu or in a vernacular in lower grades, except in Sindh where the option of Sindhi medium education is available in higher grades also. Here, English is offered as a subject. The private schools mainly offer English as the medium of instruction, Urdu as a subject, and Sindhi in Sindh. Another main difference between the two schooling systems, private and government was the well-documented poor teaching/learning of the English language in government schools (Rahman, 2003),

To address the inequality created by the growing significance of English and the poor learning of the language in the government schools catering to the relatively poor, in 2009, all the government schools switched from Urdu to English as a medium of instruction (EMI) from class I in Punjab. Later, the bar for EMI was raised to Grade III, because of the disastrous learning outcomes, owing to the low English language proficiency of the government teachers, and the home school linguistic disconnect for the low income children which populated these schools. The higher education remains mainly in the English language, with some selective subjects, at lower level offered in Urdu.

\section{Findings}

The private school participants (PSPs) had educated parents and belonged to a higher socioeconomic status than the government school participants (GSPs), a majority of whom had uneducated parents and they all belonged to low socioeconomic strata. In contrast to the use of English in the country, all GSPs reported having learnt minimal English language skills at the end of secondary school. None of the final year government school students could speak or understand English, apart from a few common words or phrases. Hamid (GSP) declared 'I can read fluently in English' only to add 'but I don't know what it means.' While all of them could speak Urdu, fluently, and a majority of them were confident in their Urdu, six of the sixteen participants all belonging to the lowest economic strata felt they could not write in the language and had difficulty reading in it also after spending 10 years in secondary school. The private school graduates expressed confidence in varying degrees in the English language, while all of them felt they had 'poor' Urdu, even when they could speak it fluently. None of the two groups in Sindh felt they had learnt Sindhi, except one from Sindhi family (her elder sister felt she did not know Sindhi) although they were all taught the language at school for at least $3-4$ years.

This paper concerns itself only with the cross cutting themes emerging from the discourse of two groups: government school participants (GSPs and private school participants (PSPs). It does not address the differences across gender, between siblings or intragroup variation in individual responses. The four themes of impact of languages in education experienced in schools within the wider language policy emerged across dimensions: cognitive; social; affective and physical. This division is only theoretical and I acknowledge the overlapping of themes across these dimensions.

\section{Cognitive dimension: participation in higher education}

\footnotetext{
1 The process of integrating and refining the theory
} 
As the medium of education changed from Urdu and English at sites of higher education, even the brightest of the GSPS found themselves struggling. Hasnat (GSG) explained:

For one thing English was there all of a sudden. In the beginning...[l] could not understand at all. Could understand nothing at all...first look up the meaning of each word and then learn. Then [we] had to learn the whole chapter...all was in English. At school there was a small book [of English]. Now there were so many thick books (Source Interview GSP, Lahore, Tamim, 2014, p. 290).

GSPs reported that even the concepts they knew well at school were difficult to connect with at college, as the terminology changed from Urdu to English. Asif (GSP) commented that when the lectures were delivered exclusively in English (often in English language classes), they could 'understand nothing at all.' Naz recalled when their group from government schools, which formed $60 \%$ of her public sector college requested the teacher use Urdu, she simply told them off, 'we had a lot of problem... we would say miss explain just a little in Urdu but she would say now you are at stage that you have to work with English.' Instead of feeling a part of the community of learning, Ayesha like all other GSPs described a strong sense of isolation in classrooms as if they were 'invisible' to the teacher, never participating. 'If we do not understand anything, how do we ask questions,' commented Sameen.

English as a medium of instruction (EMI) at higher levels also forced some GSPs to drop out of colleges. Farheen (GSP) had been studying from home because of the sociocultural constraints that made travelling alone to college difficult. She attended the college only occasionally to take exams and do assignments. Nasir (GSP) also juggled work with higher education because of the pressure to eke out a living. Both of them had to forgo their aspirations for further study, when the subjects of their choice were offered in English, as in the case of latter and when the English text book at BA level (notoriously more demanding) became too difficult for self-study. Hence, their cognitive agency for autonomous learning crippled when the text was encoded in a language they did not know. . Hence, it comes as little surprise that of the GSPs aiming at certain academic careers, only one could succeed. Others like Hasan, Akram and Aslam scored much lower at the entry point examination of their chosen academic fields, despite being among the best students at school.

In strong contrast, the PSPs continued unobtrusively in the English medium of instruction (EMI) they were accustomed with. To their delight, they now realized the symbolic power and value of the linguistic capital of English. Participating in classrooms, they strongly felt a strong cognitive advantage in terms of processing information over those from government schools. Midrah (PSP) commented that the 'Urdu medium girls' in her college class 'simply used to copy' her assignments and later after the class was over, they would come over and request her to explain the lecture to them.

The symbolic struggle for access to the cultural capital of education is evident in the discourse of the two groups at sites of higher education. The PSPs are clearly advantaged as they already possess the linguistic capital valued at higher education and this allows them to accumulate more of the cultural capital of education that can later be transformed into economic capital. Hence, the capitals that have enabled the PSPs to acquire a higher position in the social structure are multiplied. On the other hand by the devaluation of the linguistic capital of the PSPs at higher education and the increase of the significance of a language that their schools failed to equip them, the educational institutions become complicit in reinforcing the existing inequality. As the degree of academic language proficiency [English in this case] they develop in school is a crucial intervening variable in mediating their academic progress' (Cummins, 2000: 99), the PSPs either fall out of their chosen fields or drop out of education altogether. The English language becomes the tool of subtle exclusion of the dominated group (Bourdieu, 1991), and eventually their 'delayed elimination' from higher education, as it becomes a formidable and veritable force, a symbolic power too difficult to contend with (ibid.).

\section{Social Dimension: English and Gate Keeping}

There is this language barrier', Rehana reiterated 'between those who know English and those who do not' She explained the simple rule of her group 'anyone who does not know English is out.' She clarified what her own English symbolized for her, 'I can speak English, I have a good family, a good car so I can be in any group.' Unais (PSP) emphasized that Urdu medium were uncouth, 'ill mannered' and 'uncivilized.' Although he said he never had had a chance to be in the same class with the Urdu mediums, he insisted that 'Urdu mediums had bad language which was not tolerated in good institutions.'

On the other hand, Naz (GSP) explained 'we would like to be with them [those who know English] but they don't like it. They think it is kind of lower, to be friends with us.' Fahad (GSP) a good looking young man felt hesitant to come over to an elite university, at a convenient distance for an interview for this research. Later, he explained later that his hesitance 
was from the anticipation of being spoken to in English and his own inability to respond in the same language. Maria (GSG) quietly described 'I used to be silent ... when she [my friend] used to speak in English. 'I could understand to some extent', Maria said 'but I could not answer her in English ... so I would be silent.'

The symbolic power of English language as a tool for gatekeeping emerges in the discourse here, as English becomes the criteria for group memberships at the nexus of economic and cultural capitals. Hence, class based boundaries become more prominent with the tool of English. This is accompanied with 'othering, stereotyping and essentialzing' (Kubota 2004: 39), almost a 'colonial dichotomy between the Self and the Other' obvious in the language based differences accentuated in 'we' and 'they' as suggested by Unais and Naz. The one wielding the symbolic capital of English emerges as cultured and superior while the other as 'uncivilized' and inferior (ibid.).

The symbolic value of English also appeared to invest everyone with 'a sense of limits', and distances to be kept ' uniting and separating people as surely as explicit prohibitions and barriers' (Bourdieu, 1991: 123). Group membership has to be performed through the ritual of a certain language use, which accounts for the distinction of the group from others and Rehana, faithful to her group can be seen guarding the boundaries of her group with the tool of English. Given, the significance of social networks and social capital in development, this is an important dimension of inequality for the GSPs who fail to develop new powerful social networks that may lift them out of deprivation.

\section{Affective Dimension:}

Hira (PSP) explained the impact of acquiring the valued linguistic capital ,'When English is spoken others get intimidated. If only you know how to speak English it makes you feel superior. It is not about you are in studies.'A sense of owning the valued linguistic capital of English tremendously boosted the confidence of the PSPs, and infused them with a sense of superiority and power. Rehana (PSP) emphasized 'English is to command [...] tell them what to do,' discussing how she used her lesser proficient class fellows to do what she wanted. Hira (PSP) revelled in the way she used her English skills to 'manipulate' her class fellows 'for getting things done her way', 'stand out in the crowd' and 'gain attention' from those around. Midrah (PSP) reported the case of her very talented class fellow in the last year of National Arts College University:

He says [...] because I have studied in Urdu medium I don't have so much confidence. He admits it himself like it is in him. I have studied Urdu so perhaps I don't have so much idea. I am like lower than English medium. (Interview PSp, Karachi).

Faiz (PSP) disclosed that he deliberately faked an American accent to impress his class fellows and teachers. He explained that he felt delighted when his class fellows 'simply go blank' when he used difficult English vocabulary and when he used his American accent when making a presentation in his class, the students and teachers seemed to be thinking 'where is he from?'Nael (PSP) said that he was able to 'silence' others when he spoke in English. Faiza (PSP) narrated an incident when her friend was able to win a heated argument and silence a senior girl as she spoke to her in English. The crowd gathered around them started laughing at her opponent as she attempted to argue back in her broken English.

At the other end of the pole GSPs suffered from low self-esteem and losing confidence as their linguistic capital was devalued. Sameen explained:

I tell you [I] felt nothing [about being educated in Urdu medium] but when we had our English class I felt very ashamed that they (PSGs) are speaking English so well... we used to feel so guilty that if our English had been equally good the teacher would have paid attention to us... What do we do if we are from Urdu medium and English is not our language (Source: Interview GSP, Karachi)?

Kamran (GSP) explained that 'English becomes his limitation,' and 'his guilt' in classroom interaction, because he can see that he does not have what others do and it is valued. Nazia (PSP) expolated, 'if someone talks in English and we cannot answer in English, then it is like we are lower... our level is lower.' Lack of confidence, low self esteem and sense of inferiority was a major recurring theme in all GSG interviews directly linked to their limited English and devaluation of their languages at higher education institution but also in the wider social context.

It is ironical that it is at the site of higher education that GSGs first realized their own inferior position Phrases used by Sameen were echoed in the discourse of almost all GSGs 'guilty and 'ashamed' 'embarrassed' accompanied by a deep sense of powerlessness 'What do we do if we are from Urdu medium and English is not our language' said Fauzia (GSP). Cummins (2000) explains the sense of shame felt by GSPs: 
In the vacuum created by the absence of any proactive validation of their linguistic talents and accomplishments, bilingual students' identities become infested with shame. (Cummins, 2000:13).

English language, the valued linguistic capital differentially distributed by educational institutions, rationed along classbased lines, allow the PSPs to inflate their ego and deliberately attempt to divest others of their 'right to speak' or 'be heard,' is a manifestation of symbolic power (Bourdieu, 1991). Bourdieu (1991) emphasizes that 'power in symbolic form' gains 'legitimacy' through misrecognition,' of arbitrary structures as absolute and is always based on a 'shared belief':

In such a way that even those who benefit least from the exercise of power participate, to some extent, in their own subjection. They recognize or tacitly acknowledge the legitimacy of power or of the hierarchical relations of power in which they are embedded; and hence they fail to see that hierarchy is, after all, an arbitrary social construction, which serves the interests of some groups more than others (Bourdieu, 1991:23).

GSPs never question the given linguistic hierarchy or the devaluation of their language because it all seems 'common sense.' Hence, they grant legitimacy to the symbolic power exercised over them, accepting the rules of the game (Bourdieu, 1991). Their silence perpetuated by the symbolic violence perpetuated by the language policy and mediated through educational institutions that concealed the arbitrariness of the social structure and anticipated academic judgements (Bourdieu and Passeron, 1977). Hence, the 'legitimizing regimes' in which GSPs accept to be 'stigmatized' and 'marginalized' (Bourdieu, 1989 in Heller, 2008: 65).

\section{Economic dimension:}

All the participants clearly acknowledged the significance and value of English in getting access to coveted jobs, expanding businesses and all the domains of power. Against this perspective, the more the participants were at ease with their English language skills, the more confident they were in their about the success of their careers. The PSPs felt they had a strong edge over those from government schools because of their better English. Faiz declared confidently, 'I can get any job I choose....work wherever I like' because he felt there was nothing to stop him. Akram (PSP), he has always been selected for internships easily because of his English. The moment some position is announced, the class just names him 'just like that,' even when he has not even applied for it. Similarly other PSPs were quite confident that they would be preferred over someone from government schools. Midrah (PSP) in the last year of her BA in Architecture explained how during their internship placements those with good English were placed in the front offices, while others were put in back offices only.

The GSPs worried deeply. 'You need English even for a waiter's job at Pizza Hut,' commented Nazir. Atif (GSP) described how he crammed up some answers to some basic anticipated questions for his job interview. The interview, he reported was in English at the beginning but when he could not respond properly, they shifted to Urdu. Although he got the job, embarrassed by his failure in not being able to respond in the official language, he did not even ask about his salary. Now, a month into the job, he did not know what he would be paid.

The GSPs felt that even if they landed a good job they would still be haunted by the adverse effects of their poor English at workplace, which would hinder their upward mobility and their visibility in the organization. Hussein (GSP) explained 'you know it [the work] but you cannot make a presentation in Urdu... that has to be in English.' Imran (GSP) emphasized 'the boss would never take with him anyone who does not even know how to speak \{in English]. ' Khalid (GSP) only a low paid blue-collar worker in a factory, described his embarrassment when his supervisor used an English phrase asking him to hand something over. He laughed, as he could not understand. Later he asked his friend and was more prepared. Ali (GSP) detailed his career aspiration was to be a banker rather than join his father in skilled labour, only later to add that he probably would not do that unless his English improved because he did not want to lose face and not know the official language.

Poor proficiency in English particularly affected the females GSPs, who were mainly in teaching jobs, forced to accept very low salaries between PKR 1200-1500 (\$100-150). This was at a time when ordinary uneducated domestic help in urban homes were being paid around PKR 10000-15000 (\$1000-15000). Khalid (GSP) after working for 4 years at a salary of PKR 1000 (\$9000) that her employer would not increase, left her teaching job to start her own business of embellishing laces. This was possible with her linguistic capital of the national lingua franca Urdu and different local languages that she had picked up from the collage of communities around her home enabled her to bring work to the local women who had restricted mobility because of certain ethnic norms they followed, and spoke the little understood ethnic language. Though without any economic capital, she engaged with the market and brought work to these women at home. Her work was 
flourishing and she was making enough to pay for the school fees of her younger brother, while saving for her dowry. An act of agency and self-reliance that was possible because of the repertoire of local linguistic capital.

Bruthiaux (2002) emphasizes that if the aim is to transform the perception of the poor about their 'economic potential', it is the first language rather than 'a potentially unfamiliar language of wider communication' that can assist in this regard ( $p$. 275). Khalida (GSP) was only able to find her way out of adversity and help others to do the same by being able to connect with those around her with her linguistic capital. Had she not known the local languages, the other community women would have felt off the radar and neither would she have been able to unleash her own potential. Bourdieu's (1984) argument that all capitals are interlinked with economic capital and also convertible into it and back is validated. The GSPs beginning with lower economic capital have lesser access to the symbolic capital of English and in turn have lesser access to economic capital into which their linguistic capital is convertible. Hence, they feel that their linguistic capital has lower exchange value in the market. In contrast, PSPs, with higher economic capital can be seen to multiply it with the use of the symbolic capital of English.

One can observe the inscription of the social order on the perceptions of the GSPs, with the marginalizing symbolic power of English language. 'Objective limits [of not being able to access the linguistic capital of English] become a sense of limits [things that can be done or not done], forcing self-deselection from valued career choices (Bourdieu, 1986). However, the possibility of alternate discourse becomes available, when one side steps the given norms- not play the game. Hence, we find that by giving up the chase of the symbolic capital of English. Faiza makes the best of what she has, her local linguistic capitals and fares much better in the economic dimension.

\section{Physical Health}

The findings revealed the linguistic capital of English, also gave an advantage to the PSPs in their health management, while subtly marginalizing the GSPs. Although the main language spoken was Urdu at the hospitals, almost all written documentation was in English. There was hardly any role for the regional languages, although the participants explained that they felt a bonding with the doctor, if he/ she used their regional language. Faiza (PSP) explained that her understanding of dengue fever that had taken on epidemic magnitude at the given time was substantially improved when she attended a health Seminar hosted by a leading hospital in the city. These health seminars by medical colleges were held occasionally for public awareness. These were free of charge, with the purpose to raise public awareness about an important health issue. The only caveat was that it was almost always in English. This meant an implicit exclusion of those who did not know English, though these were most probably also the most vulnerable.

Amjad (PSP) argued that because of his command of English, he was able to research his father's ailment over the internet and discuss it in detail with the doctor. Faiz (PSP) shared that once he started to speak in English with the doctor during a consultation session for his father, the doctor started to explain everything to him in detail, ignoring his Uncle and father, who were also in the room. Hira (PSP), a final year medical student explained that because the doctors have studied everything in English, it is much easier for them to discuss the health problem in English. Pointing to another aspect of the problem, she highlighted a major problem for the doctors in communicating with patients, when the latter they came from remote rural areas did not speak Urdu. 'We are just desperately trying to find someone who can understand the patient,' she commented. She also argued that the problem remained otherwise also with urban patients who did not speak English, as the doctors tended to constantly code switch into English 'Any word of English that slips through you is not there for them as good as never spoken', Hira stressed.

Although the GSPs felt that knowing Urdu resolved their problem of accessing health based information, they inadvertently shared a vague sense of vulnerability. 'Even a disposable syringe has English on it,' commented Khalid. Shafia pointed out the medical literature in English, which accompanied most of the medicines. Even when information in Urdu was given at times, the information in the latter was selective and much less. Similarly, the information on off the shelf medicines or cosmetics etc. being in English gave the PSPs a much broader range of choices than that offered to those who did not have the valued linguistic capital.

These findings support the results of the systematic review of studies by Timmins (2000), published in biomedical journals from 1990-2000, exploring language barriers in terms of access to health care, quality of care, and health status outcomes that revealed a strong evidence of language barrier affecting access of care in $55 \%$ of the studies; while $86 \%$ of the studies 
suggested 'a significant detrimental effect of language barriers' on quality of care (Timmins, 2000: 1). In addition every two out of three studies found 'language to be a risk factor for adverse outcomes' in terms of health (Ibid.).

The symbolic power of English language in the given context can be seen perpetuating marginalization of the GSPs in the dimension of health also. Its power to activate world vision/ ideologies, working on the objective structures is evident. The doctor talks to young Faiz, perceiving him to be more 'educated' because of his English, or because of his own inability to explain himself in the local language, or not understand an ailing patient because of the language barrier, the given structures or the given hierarchy of languages is never argued. It is English not the local language knowledge that is symbolically desired, not practically required. Bourdieu argues that the symbolic power of language:

Inclines some people to maintain their rank and distance and others to know their place and be happy with what they are, to be what they have to be, thus depriving them of the very sense of deprivation. (Ibid.)

\section{Conclusion}

The paper explored the impact of differentially distributed languages in education in institutions within the national language policy. Poverty was conceptualized as multidimensional, relative and in the space of 'capabilities,' (Sen, 1990). The findings reveal that the symbolic power of the linguistic capital of English, derived from its unequal distribution, its scarcity and the misrecognition of its importance as natural and common sense, marginalized the already disadvantaged government school participants in multiple dimensions: economic, social, affective and physical. In contrast, private school participants benefited from the given structure in all the above. While the PSPs were able to multiply their capitals because they already had the valued linguistic capital of English, which itself was a stake in symbolic struggle for distinction, the GSPs suffer from relative poverty because of two main reasons: a) they do not have the symbolic capital of English and b) the symbolic power of English, and its legitimization by educational institutions and the wider language policy working through all other institutions make it difficult for the GSPs to question the given order.

The answer however is more complex than providing everyone English, as this would not resolve the problem of the patient whose doctor does not understand his/ her language and risks misdiagnosis. Neither does it resolve the issue at the level of small businesses, where it is not English but local languages that are more in use. The answer lies in accepting the linguistic diversity of the context, legitimizing them through not only educational institutions but also the wider institutions of the government, while also equipping everyone with the international lingua franca. Hence, thereby challenging the symbolic power of English.

From a development perspective, the study matches the results of Robinson's (1996), study that showed the local language use was decisive in involving people and shifting the 'locus of power' to them (p. 4). The exclusion of local languages makes it difficult for people to draw local resources and knowledge. For instance, change of terminology made it difficult for the GSPs to reintegrate concepts that they had already learnt at school at higher education. The study showed that unless the linguistic and cultural capital is 'concordant' with existing structures, participation is bound to be limited (Bourdieu, 1991). And it is precisely 'the question of what capital is at stake and how it is valued which is constantly at issue in social interactions' (Grenfell et al., 1998: 25).

\section{References}

[1] Blunden, A. (2011) Bourdieu on status, class and culture, retrieved from http://home.mira net/ andy/works/bourdieu-review.htm

[2] Bourdieu, P. \& Passeron, J. C. (1977a) Reproduction in education, society and culture, R. Nice (trans.)

[3] Bourdieu, P. (1977b) An outline of a theory of practice. (London: Cambridge University Press).

[4] Bourdieu, P. (1984) Distinction: A social critique of the judgment of taste, R.Nice (trans.) (Cambridge, MA: Harvard University Press).

[5] Bourdieu, P. (1986). The forms of capital. In J. Richardson (Ed.), Handbook of theory and research for the sociology of education (pp.241-258). (New York: Greenwood Press).

[6] Bourdieu, P. (1991) Language and symbolic power (Cambridge, MA: Harvard University Press).

[7] Bruthiaux, P. (2002) Hold your courses: language education, language choice, and economic development. TESOL Quarterly, 36: 275-296. Doi:10.2307/3588414 
[8] Cummins, J. (2000) Language, power and pedagogy (Clevedon: Multilingual Matters).

[9] Cunningham, J. (1993) Habitus and misrecognition. Retrieved from http://www.ed.uiuc.edu/eps/PESYearbook/93_docs/CUNNIGH.HTM.

[10] Devine, J. (1994) Literacy and social power, in: R. M. Ferdman, R. M. Weber, A. G. Ramezs (Eds)

[11] Fakuda-Parr, S. (2003) The human development paradigm: operationalizing Sen's ideas on capabilities, Feminist Economics Vol. 9, 301-317

[12] Gee, J. (1989) What is literacy?. Journal of Education, 171(1), 18-25.

[13] Grenfell, M., and James D. (1998). Bourdieu and education: acts of practical theory (London: Palmer Press).

[14] Kaplan and Baldauf, (1997). Language Planning from practice to theory (Clevedon: Multilingual Matters)

[15] Kubota, R. (2004) Critical multiculturalism and second language education, in: K. Toohey, B.Norton (Eds) Critical pedagogies and language learning (Cambridge: Cambridge University Press).

[16] Lantolf, P. ( 2001) Sociocultural theory and second language learning (Oxford : Oxford University Press).

[17] Literacy across languages and cultures (Albany, NY: The University of New York Press), 221-

[18] Markee, N. (2002), Language in development: questions of theory, questions of practice. TESOL Quarterly, 36: 265-274. doi:10.2307/3588413

[19] Nyati-Ramahobo, L. (2004) The language policy, cultural rights and the law in Botswana Series A: General \& Theoretical Papers No. 613, Essen. Universität Duisburg-Essen

[20] Rahman, T. (2006) Language and politics in Pakistan (Karachi: Oxford University Press).

[21] Robinson, C. D.W. (1996) Language use in rural development: An African perspective (New York, Mouton de Gruyter). Sciences, 20(1), 5-28.

[22] Sen, A. (1990) Development as capability expansion, in: K. Griffin, J. Knight (Eds) Human development

[23] Skutnab-Kangas, T. (1998) Human rights and language wrongs-a future for diversity?, Language

[24] Tamim, T. (2014) The politics of languages in education: issues of access and participation and inequality in the multilingual context of Pakistan, British Educational Research Journal , vol., 40 (2), 280-299.

Tollefson, J. (1991) Planning language, planning inequality: Language policy 